\title{
Médiévales
}

Langues, Textes, Histoire

75 | automne 2018

Traductions du Moyen Âge

\section{ARNAU DE VILANOVA, Regiment de sanitat per al rei d'Aragó. Aforismes de la memòria}

Edició crítica d'Antònia CARRÉ, Barcelone, Universitat de Barcelona

(Filologia UB), 2017, 406 p.

\section{Marilyn Nicoud}

\section{OpenEdition}

\section{Journals}

\section{Édition électronique}

URL : https://journals.openedition.org/medievales/9637

DOI : $10.4000 /$ medievales.9637

ISSN : $1777-5892$

\section{Éditeur}

Presses universitaires de Vincennes

\section{Édition imprimée}

Date de publication : 15 octobre 2018

Pagination : 256-257

ISBN : 978-2-84292-861-2

ISSN : 0751-2708

\section{Référence électronique}

Marilyn Nicoud, "ARnAU de VILANova, Regiment de sanitat per al rei d'Aragó. Aforismes de la memòria ", Médiévales [En ligne], 75 I automne 2018, mis en ligne le 15 octobre 2018, consulté le 24 avril 2022. URL : http://journals.openedition.org/medievales/9637; DOI : https://doi.org/10.4000/medievales. 9637

Ce document a été généré automatiquement le 24 avril 2022.

Tous droits réservés 


\title{
ARNAU DE VILANOVA, Regiment de sanitat per al rei d'Aragó. Aforismes de la memòria
}

\author{
Edició crítica d'Antònia CARRÉ, Barcelone, Universitat de Barcelona \\ (Filologia UB), 2017, 406 p.
}

Marilyn Nicoud

\section{RÉFÉRENCE}

ARNAU DE VILANOVA, Regiment de sanitat per al rei d'Aragó. Aforismes de la memòria, edició crítica d'Antònia CARRÉ, Barcelone, Universitat de Barcelona (Filologia UB), 2017, 406 p.

1 Médecin célèbre en son temps et parmi les mieux connus du Moyen Âge, Arnaud de Villeneuve (ca 1240-1311) continue à juste titre de susciter l'intérêt des médiévistes, aussi bien pour son œuvre spirituelle qu'a fortiori médicale. Professeur à l'Université de Montpellier et médecin des princes (aussi bien laïques que d'Église), il est l'auteur d'une œuvre prolifique qui, dès son époque, fut très largement diffusée, sous forme manuscrite puis imprimée, mais aussi grâce à de nombreuses traductions en différentes langues vernaculaires. Ses ouvrages, écrits en latin, la langue scientifique en usage, font depuis 1975 l'objet d'une entreprise d'édition critique (Arnaldi de Villanova Opera Medica Omnia - AVOMO), publiée par l'Université de Barcelone. Mais les historiens se sont aussi intéressés à la vulgarisation de ses traités, aussi bien en hébreu qu'en castillan et en catalan. Antònia Carré propose ici une nouvelle édition combinée du régime de santé que le médecin dédia au roi d'Aragon Jacques II (1291-1327) au début du xive siècle (probablement entre 1305 et 1308) et de ses Aphorismes pour la mémoire, dans leurs traductions catalanes respectives.

2 Le Regimen sanitatis ad regem Aragonum, dont la version latine a été par deux fois éditée récemment ${ }^{1}$, avait déjà fait l'objet, dès 1947, d'une publication par Miquel Battlori de sa translation catalane par Berenguer Sarriera $(\dagger 1310)^{2}$. Cette dernière était alors connue 
par un unique manuscrit incomplet (Madrid, Biblioteca Nacional de España, ms 10078, $1^{\text {er }}$ quart du XIV siècle). Mais l'examen minutieux d'une deuxième traduction abrégée de ce texte (Città del Vaticano, Biblioteca Apostolica Vaticana, Barb. Lat. 311, $1^{\text {re }}$ moitié $\mathrm{du} \mathrm{xv}^{\mathrm{e}}$ siècle), et la découverte d'un deuxième témoin de cette première version (Barcelona, Biblioteca de Catalunya, ms. 1829, mi-Xve siècle) justifient une nouvelle édition, qui bénéficie par ailleurs des acquis des travaux les plus récents, non seulement sur Arnaud de Villeneuve, mais également sur les entreprises de traductions en catalan des œuvres scientifiques médiévales ${ }^{3}$. Depuis une trentaine d'années en effet, la part des études sur la vernacularisation des savoirs (terme moins ambigu que celui de vulgarisation) s'est accrue, mettant en lumière la divulgation, sous forme de traductions ou d'écritures en langues vulgaires, dans des aires géographiques diverses, d'un grand nombre de textes dans les domaines techniques, scientifiques et médicaux. La Catalogne, loin d'échapper à ce phénomène, s'y révèle au contraire un terrain particulièrement fécond.

3 Antònia Carré, dans une longue introduction, remet en perspective la première traduction catalane du Regimen sanitatis, œuvre la plus diffusée parmi la riche production d'Arnaud puisqu'on conserve 68 manuscrits datés des $\mathrm{XIV}^{\mathrm{e}}-\mathrm{XV}{ }^{\mathrm{e}}$ siècles de la version originale en latin, sans compter donc des adaptations en catalan, en hébreu, en français, en allemand et en italien, dès les $\mathrm{XIV}^{\mathrm{e}}$ et $\mathrm{XV}^{\mathrm{e}}$ siècles, et, aux XVI ${ }^{\mathrm{e}}-\mathrm{XVII}{ }^{\mathrm{e}}$ siècles, une nouvelle version française et une castillane. Cette première transposition en catalan fut réalisée du vivant même de l'auteur et très peu de temps après la rédaction latine, entre 1305 et 1309 sans doute. Elle est l'œuvre du chirurgien de cour Berenguer Sarriera, lui-même issu d'une lignée de chirurgiens, et fut composée à la demande de la reine Blanche d'Anjou, épouse de Jacques II, décédée en 1310. Cette entreprise témoigne du rôle joué, dans la transmission en langues vulgaires des savoirs médicaux, par le patronage curial et par ces chirurgiens lettrés, formés dans les studia à la chirurgie rationnelle (c'est-à-dire à une discipline fondée sur les savoirs médicaux scolastiques) et à la langue latine. Avant Berenguer Sarriera, et comme le montrent les travaux de M. R. McVaught, Guillem Corretger et Bernat de Berriac avaient transposé en catalan la chirurgie de Teodorico Borgognoni. La deuxième version catalane du Regimen sanitatis date elle aussi du premier quart du $\mathrm{xvI}^{\mathrm{e}}$ siècle et si son auteur demeure anonyme, il y a fort à croire, selon les recherches d'Antònia Carré, qu'on se situe dans un même milieu professionnel.

4 S'il ne reste aujourd'hui que très peu de témoins des deux versions catalanes du Regimen, l'étude des possesseurs, menée à partir d'inventaires post mortem, souligne une diffusion variée qui s'étend de la cour et des milieux aristocratiques au monde urbain lettré, où figurent, aux côtés d'un notaire et d'un juriste, des membres de la profession médicale au sens large (un médecin, trois chirurgiens et un apothicaire), soit un lectorat qui, au Moyen Âge, s'est toujours montré friand de cette littérature diététique volontiers didactique et divulgative, y compris lorsqu'elle est rédigée en latin. Qui dit traduire ne dit pas automatiquement trahir, pour reprendre le jeu de mot que permet la langue italienne, de tradurre à tradire. Et même si le texte d'Arnaud, à l'image de ses devanciers du XIII ${ }^{e}$ siècle, ne révèle pas de véritable difficulté en raison de son caractère pratique, la traduction de Berenguer Sarriera se montre en général fidèle à son modèle, suivant la technique du mot à mot (de verbo ad verbum) généralement utilisée par les auteurs. Les erreurs de lectures ou d'interprétation sont plus sûrement imputables soit 
au copiste, soit au manuscrit que le traducteur a utilisé. L'éditrice propose ici une étude serrée de la langue employée dans les manuscrits et des pratiques de traduction.

Judicieusement accompagnée par la translation en catalan des Aphorismi de memoria d'Arnaud de Villeneuve (qui prisait fort un genre d'écriture en vogue depuis l'Antiquité dans le discours médical, car ils délivrent principalement des règles d'hygiène pour améliorer les capacités mémorielles), l'ouvrage d'Antònia Carré vient apporter une nouvelle pierre substantielle à l'édifice éditorial des Opera omnia Arnaldi de Villanova, en éclairant leur diffusion en vulgaire. Celle-ci témoigne, en cette fin de Moyen Âge, d'un intérêt marqué pour la vernacularisation des savoirs en réponse à une demande sociale toujours aussi forte, en matière notamment d'hygiène et de soins du corps. Le régime d'Arnaud de Villeneuve, qui allait devenir dans sa version latine un véritable «bestseller » de la littérature diététique, ne pouvait guère échapper à une telle entreprise, dont l'auteur put même voir la concrétisation de son vivant.

\section{NOTES}

1. ARNALDI DE VILLANOVA regimen sanitatis ad regem Aragonum : un tractat de dietètica de l'any 1305, éd. A. TRIAS TEIXIDOR, Barcelone, 1994 ; ID., Opera medica Omnia, X.1, Regimen sanitatis ad regem Aragonum, éd. L. GARCía BALLESTER et M. R. MCVAUGH, Barcelone, 1996.

2. ARNAU DE VILANOVA' Obres catalanes, vol. II, éd. M. BATLLORI, Barcelone, 1947.

3. L. CIFUENTÈs, La ciència en català a l'Edat Mitjana i el Renaixement, Barcelone/Palma, $2^{\mathrm{e}}$ éd., 2006.

\section{AUTEURS}

\section{MARILYN NICOUD}

Université d'Avignon - UMR 5648 